\title{
INTERACTIONS BETWEEN PARENTS AND STAFF OF
HOSPITALISED CHILDREN
}

\section{Lynn Priddis and Linda Shields studied history to consider whether parents who wish to stay with their child following admission are any more welcome today than in the past}

Summary
The Platt report (Ministry of Health 1959)
recommended that hospitals provide for parents
to stay with sick children. This review, of how
hospitals have or have not followed this guidance,
assesses the literature and includes insights into
research on the theory of attachment. The authors
conclude that, although parents are commonly
to be found on wards with sick children, this
is not often systematically encouraged or even
understood. However, recent initiatives to improve
communication between staff and the parents of
children admitted to hospital are encouraging.
Keywords
Attachment, family-centred care, hospitalised
children, parents

THE ROLE OF the parents of children in hospital has changed profoundly in the past 50 years (Shields and Nixon 1998). Until the 1960s, parents were excluded from the wards, often for the entire duration of the child's admission, a policy believed to be in the best interests of the child (Forres 1953). In 1959, the Platt Report, which investigated the care of children in hospital in Britain (Ministry of Health, Central Health Services Council 1959). It recommended that parents be allowed to stay with their hospitalised child, and that accommodation be provided for them. Following the publication of the Platt Report, consumer-led organisations in the Western world, including Britain, Australia, North America and other European countries, lobbied for the Platt report's recommendations to be accepted as policy in children's hospitals and wards (Shields 1999). However, change has taken a long time to implement fully, and it is still not certain that parents are welcomed without reserve in all places where children are nursed. This article reviews the literature on the interactions between parents and hospital staff from a historical perspective. Such history suggests that much of the difficulty in this relationship is due to lack of understanding by parents and hospital staff of the research findings on which the Platt Report was based.

\section{Methods}

A literature search was undertaken in 2008 using Medline, the Cumulative Index of Nursing and Allied Health Literature and sources such as state and historical libraries in Australia and Britain, including the library of the Association for the Welfare of Children in Health Care in Australia and the Royal College of Nursing and Wellcome libraries in the UK. More than 50 publications, dating from 1888 to 2008, from nursing, allied and medical literature, formed the basis for this article.

From the literature search papers that attended to the history of parents in children's wards in 


\section{An attuned parent is one who accurately} perceives and interprets the infant's

\section{attachment signals and responds promptly}

hospitals since 1888, and the extent to which the recommendations of the Platt report in 1959 have been implemented in the past 50 years, themes were identified. From these papers common themes were identified across the first ten papers and then the remaining papers were examined in the light of these themes. Where additional themes were identified these were added to the list.

\section{Results and discussion}

From the first world war to after the second world war The writings of Wood in 1888 and Yapp in 1915 show that during this period children's wards were run in ways that were sensitive to the emotional needs of children. However, by the 1920s when infection became a perceived problem in children's wards, this had changed to a more industrialised environment and parents were excluded. Hospitals became grim places for children (Jolley 2004, Jolley and Shields 2009)

The evacuation of British cities in the second world war, which saw thousands of children removed from their parents, resulted in a change of thought about the presence of parents in children's wards (Jolley and Shields 2009) which had already been advocated by some earlier pioneers. The routine exclusion of the parent in the care of hospitalised children had been questioned in the 1920s by Sir James Spence, who set up the first mother and baby unit in Newcastle upon Tyne in the UK (Court 1975). Spence believed fervently that breastfed infants should not be separated from their mothers (Spence 1947). However, few members of the medical profession shared his views at that time (Vaughan 1957). In New Zealand in the 1940s, two surgeons admitted mothers with their infants when they came to their clinic for plastic surgery, demonstrating that infants did better if their mother was present (Pickerill and Pickerill 1946).

The select parliamentary committee set up to examine the care of children in hospitals in 1958, which ultimately published the Platt report, was strongly influenced by emerging evidence on the importance of the infant's early ties to the mother. Burlingham and Freud $(1942,1944)$ worked with children whose parents were unable to care for them during the second world war (usually the father was fighting and the mother engaged in war work), and described many of these children as 'hard to reach'. In contrast, the authors found that young children who suffered physical trauma maintained psychological stability if they were with their mothers.

In the United States, Levy propounded that young children who had undergone surgery suffered less emotional trauma if their mother accompanied them (Levy 1945a, 1945b), and Renee Spitz documented the incidence of anaclitic depression among infants separated from their mothers after the age of six months (Spitz and Wolf 1946).

Robertson and Bowlby Two British men, James Robertson and John Bowlby, were arguably most influential in research and theory about the necessity of parental presence during a child's hospitalisation (Alsop-Shields and Mohay 2001). Robertson (1970) presented filmed evidence of the distress experienced by children left alone in the alien world of hospitals, highlighting the emotions that accompany disruption of a child's attachment to the mother. Bowlby, whose own early work linked deviant behaviour among young children with separation from their parents, began to pull these insights together in his seminal volumes on separation and loss (Bowlby 1969, 1973, 1980).

Taking an ethological perspective, Bowlby noted that there is a species-wide imperative for the young to stay close to a protector. He proposed that infants are similarly programmed to signal needs for comfort and protection. The infant's survival depends on the stable presence of the mother or other attachment figure who will consistently perceive and respond to these signals. In the absence of sensitive responsiveness, the infant becomes extremely distressed. This proposition was supported by Harlow's concurrent evidence that rhesus monkeys fed by a wire surrogate mother failed to thrive (Harlow and Zimmerman 1959) and by Fanselow (1994) who, working with animals, documented genetically determined motor patterns available early in life to maximise survival.

Bowlby's work immediately stimulated research into the mother-infant bond, which led to research on children admitted to hospital. Using the 'strange situation', Ainsworth and Wittig (1969) found evidence of differences in quality of attachment that are influenced by maternal responsiveness to the infant. Later, with other colleagues, they showed how to measure and classify these differences (Ainsworth and Wittig 1969, Ainsworth et al 1978). An attuned parent is one who accurately perceives and interprets the infant's attachment signals and responds promptly and adequately. Infants respond to such care co-operatively and become secure and 
well socialised. Babies who experience relatively insensitive parenting tend to be fussy, demanding, uncooperative and generally difficult to handle. In their 1978 paper, Ainsworth and her colleagues identified mutual sensitivity and responsiveness as the foundation of a secure attachment relationship (Ainsworth et al 1978).

\section{Nurses' reactions}

Nurses' attitudes were also a subject of research. A Canadian study found that nurses were pleased to have parents stay with their children (Fleury et al 1954), whereas other workers showed that nurses were not convinced that this was in the best interests of the child (Gofman and Schade 1957). Some were hostile to the idea (Aubuchon 1958), or thought that the parents' presence undermined the relationship between nurse and child (Frank 1952). Godfrey's study (1955) of paediatric nursing care described ways to ameliorate the emotional trauma children experienced following separation from their parents, but did not advocate that parents should stay in the hospital (Godfrey 1955). This suggests that some of the thinking which informed the Platt Report in 1959 (the stress caused by separations) was available to relevant personnel in the 1950s, and that nurses wanted to reduce this stress but did not have the knowledge that the only way to assist the child was to prevent the separation itself (Jolley 2004).

After the Platt report The need to minimise child-parent separations in hospital situations has been promulgated widely since the Platt Report, but perhaps not always with full information about why this is necessary and how deleterious the effects of separations can be. Roy Meadow conducted a research project which he claimed proved that a mother would rather be home caring for her other children than sitting at the side of the bed of a child who would, in normal circumstances, not spend much time with the mother at all. Meadow called her the 'captive mother' (Meadow 1969). According to Jongkees (1955), doctors thought that the presence of parents inhibited the recovery of their children, Ten years later, Rendle-Short would report that doctors advocated strongly for parental presence (Rendle-Short 1965).

By the 1980s, in view of the combined weight of the Platt Report, the consumer-driven movements in the Western world and accruing data from international research, one would have expected dramatic change in the way children were cared for in Western hospitals and a concomitant improvement in the relationship between parents and staff. A survey of Australian hospitals in the early 1980s, however, showed that parents were still not welcomed in some hospitals (Simmons 1983). By this time, research into the relationship between parents and staff had become an important field of exploration, with nurses' attitudes to parents' participation the first to be targeted.

More recently, and alarmingly, it is apparent that little has changed. Research since 2005 has shown that parents, although allowed to accompany their child, are often ostracised by nursing staff if the nurses do not sanction the parents' approaches to their children; that nurses take on a gatekeeping role inappropriate to the care they are giving; and that parents are resentful when they perceive that they are being 'made' to do the nurses' work, such as feeding, bathing and comforting (O'Haire and Blackford 2005, Roden 2005, Coyne 2008, Fegran et al 2008).

\section{Nurses' attitudes to parents}

Much of the research on interactions between parents and staff is from the UK and North America, with Australia and the Nordic countries also contributing. In one of the first quantitative studies into nurses' attitudes to parent participation, Seidl and Pilliteri (1967) developed a 24-item self-report measure known as the Parent Participation Attitude Scale (PPAS). Statistically significant findings showed that nurses with degrees, senior nurses and nurses with very young children were most accepting of parental participation (Seidl 1969).

Gill $(1987,1993)$ used an updated version of the PPAS in two American studies of registered nurses and found similar results that demonstrated the influence of marital status, education and seniority on the acceptance of parents within the hospital. Johnson and Lindschau (1996) used a modified version of the PPAS with 62 Australian nurses.

They compared their 'acceptance' scores with personal characteristics such as area of work, educational status, years of working with children and whether the staff were married or had children of their own. Unlike Gill's work, no significant differences were found. It is difficult to know whether to attribute this contrasting result to cultural factors, the three-year time gap between

$$
\begin{aligned}
& \text { According to Jongkees (1955), doctors } \\
& \text { thought that the presence of parents } \\
& \text { inhibited the recovery of their children... }
\end{aligned}
$$




\section{Few nurses felt comfortable with parents} carrying out complicated tasks such as

\section{caring for their child's intravenous infusion}

studies or variables such as sample size. The PPAS is somewhat dated now in that it is narrow in scope, focusing only on contextual variables such as education level, seniority, day or night shift and length of service. Development of a broader scale that includes variables such as self-confidence, empathy and understanding of the attachment needs of children is required.

Other investigators in this era took a qualitative approach to the issue (Knafl et al 1988, Brown and Ritchie 1989, 1990). Common elements in these studies included nurses' belief that they should carry out technical procedures while parents attended to the physical needs of the children. Investigators identified a five-factor typology of satisfaction with nurse-parent relationships in the children's hospital, ranging from 'satisfying and flexible' reciprocal relationships to more difficult 'adversarial' interactions where disempowerment and control were issues for the nurses.

In 'negotiated' relationships, nurses and parents mutually adapted their communication and behaviour, although some relationships had started from an adversarial stance. 'Asynchronous' relationships occurred when neither nurses nor parents could attune to each other's needs or communications, and 'ineffective' relationships were identified when nurses felt unable to help as much as they would have liked.

Further research The above classification could help structure further research. A content analysis of the data showed that the nurses perceived that both they and parents provided psychosocial, medical, technical and basic care for the children. Nurses expected parents to be active in this and to be advocates for their children. However, nurses felt they themselves should act as gatekeepers to the parents' roles, setting limits on what the parents were allowed to do and supervising them when caring for their children.

Conflicts originated from a lack of understanding of parents' roles and lack of negotiation with parents as to what these roles might be. Few nurses felt comfortable with parents carrying out complicated tasks such as caring for their child's intravenous infusion, not trusting the parents to undertake such tasks competently. When parents tried to advocate for their child, they were sometimes seen as demanding. Some nurses felt that some parents, particularly those who lived in, were more likely to socialise with the other parents than care for their child. This is strikingly reminiscent of a comment by Aubuchon (1958) that 'the average parent takes more interest in the child in the next bed than he does in his own'.

As this research developed, similar results were found in studies that combined interviews and observation to examine the perceptions of the parents' needs by staff and by parents (Callery 1997a, 1997b). Nurses tended to attribute negative responses by parents to parents' personalities, rather than try to determine if the responses were related to what was happening to their children. Parents' demands often led to time management problems and, although staff recognised that parents were distressed by the child's admission, little work was done to improve communication.

Family-centred care was said to be used by the nurses in the sample, but planning parental involvement was most often ad hoc. Nurses agreed that parents should be involved in the child's care, but had little idea of how to include them in a systematic way. The term 'family-centred care' began to be widely used, although to date consensus of what this comprises has not been achieved (Jolley and Shields 2009).

\section{Policy and practice}

This lack of congruence between policy and practice of family-centred care was highlighted in a study of the delivery of paediatric care in four countries (Australia, Britain, Indonesia and Thailand). It found that, whereas hospitals generally did have either formal or informal policies for family-centred care, it was not in reality being practised (Shields 1999). Some studies have examined the interactions between parents and health professionals in countries beyond the Western world, and these clearly demonstrate problems related to lack of paediatric-trained staff, lack of any staff, pressure on parents to perform nursing duties, poorly resourced settings and lack of understanding of the need for effective relationships between parents and healthcare staff (Pongjaturawit et al 2006, Aein et al 2009, Manongi et al 2009).

These papers highlight again the question of whether in the second half of the 20th century nurses or parents understood why it was necessary for parents of children admitted to hospital to be present with them. Today we recognise that when children's stress levels rise they rely on their parents to help them manage this stress and anxiety (Slade 2005, Fonagy and Target 2005), or panic can set in. 
In later childhood, calming takes the form not so much of rocking and soothing but of talking through the situation (Slade 2005, Fonagy and Target 2005). The parent listens to the fear and accepts it, and together parent and child reality-test the situation and perhaps construct strategies to combat the anxiety. The parent is in hospital for this, not to relieve the nurses of physical or medical duties, and there is no need for either party to feel threatened if these needs of the children are understood.

\section{Hospital settings where the lessons are learned} Some interesting work has emerged from the International Anaesthesia Society (McCann and Kain 2001, Kain et al 2004). This group is aware of children's pre-operative anxiety and its manifestations in such behaviours as enuresis, feeding difficulties, sleeping difficulties, apathy and withdrawal, while recognising individual differences. They report consensus among 72 anaesthetists of the need to treat anxiety before surgery. Their work acknowledges separation as a basic anxiety source and understands that this is normal, but perhaps fails to recognise the lifelong importance of attachment figures in times of stress (Bowlby 1969).

Control of anxiety, or any heightened emotion, is a self-regulatory function and depends for healthy development on the infant's experience of being calmed and soothed over time by a nurturing mother or attachment figure. This is not something that can be controlled by cognition alone (Ainsworth et al 1978).

A large-scale study by (Kain et al 2004) investigated the actual extent of parental presence in hospital operating rooms, and found that some small headway with parental presence was being made. A meta-analysis by Yipp et al in 2009 suggested, however, that parental presence during induction of anaesthesia did not reduce the child's anxiety.

Preparing parent and child We can conclude from these studies that many anaesthetists do understand the trauma caused by the non-availability of the attachment figure. The task that remains is for staff to fully understand this and to prepare parents for their role in managing their child's anxiety. This will involve fully preparing the parent and the child. The parent must be coached to build the child's trust in staff and to prepare the child for separation from the parent. In this way the parent remains separated from any role in painful or traumatic procedures.

\section{Community considerations}

Other innovative approaches that build on historical lessons to improve interactions between parents and health staff have been reported. Using Fawcett's (1989) dimensions for the development of models of care, Shields (2002) developed the Parent-Staff Interaction Model of Paediatric Care. This offers a way of planning and implementing care regardless of the class, education or knowledge levels of parents and staff between whom the interaction is taking place. The model provides a framework for raising consciousness about roles and interactions of parents and staff in the hospital.

Of course, such interactions do not occur solely in hospitals. Recent work (Priddis 2008, Priddis and Wells 2010) describes a collaborative partnership between community and child health nurses and a university psychology department to develop a programme whereby nurses assist parents when infant distress appears to be connected to difficulties with the calming and soothing function of the attachment figure. The Tuned In Parenting Programme (Priddis 2008) was developed within the framework of attachment theory, and an institution-wide approach to staff training was adopted. Qualitative evaluation of the programme after three stages showed that the parent/child dyad, the nurses and the organisation benefited from this initiative.

\section{Conclusion}

Fifty years after the Platt report, changes in children's health services around the world have led to vast improvements in interactions between parents of hospitalised children and the staff who care for them. However, we cannot be complacent. The British recommendations in 1959 for parental presence on the wards were based on theory and research which underlined the importance of a soothing and calming attachment figure when an infant or small child is frightened and anxious. These are the main reasons behind encouraging parents to accompany their sick children to hospital, but are still not widely recognised. Some hospitals expect parents to help with carrying out some of the more frightening procedures, a situation that can result in long-lasting trauma for child and parent.

There were some 'shining lights' in the literature reviewed. Particularly encouraging was the informed stance of the International Anesthesia Research Association (Kain et al 2004), whose

\section{Fifty years after the Platt report, changes in children's health services around the world have led to vast improvements}


members were familiar with the attachment literature and understood the importance of reducing fear in surgical situations.

This study has highlighted the hospitalised child's need for a 'safe base', usually the main attachment figure, and the importance of this concept in the training of health professionals involved in their care. Staff who understand the nature of secure, as well as insecure, parent-child relationships will be invaluable in making sense of parent-child interactions on the wards, and understanding staff-parent interactions will ultimately lessen anxiety and stress for all parties. At the same time, not all mothers will intuitively know why they have been enlisted into the ward team. Perhaps some explanation of what is expected of them should become a regular part of admission procedures.

\section{Online archive}

For related information visit our online archive of more than 6,000 articles and search using the keywords.

\section{Acknowledgement}

The authors would like to thank Professor Jim Nixon, associate professor, The University of Queensland, Brisbane, Australia, for his support

Lynn Priddis is senior lecturer, schoo of psychology, Curtin University Health Innovation Research Institute, Perth, Linda Shields is professor of paediatric and child health nursing, Curtin University, and Child and Adolescent Health Service, Perth, and honorary professor, department of paediatrics and child health, University of Queensland, Brisbane, Australia

\section{References}

Aein F et al (2009) Parental participation and mismanagement: a qualitative study of child care in Iran. Nursing and Health Science. 11, 3 221-227.

Ainsworth MDS, Wittig BA (1969) Attachment and exploratory behaviour of one-year-olds in a strange situation. In Foss BM (Ed) Determinants of Infant Behaviour $1 V$. Methuen, London.

Ainsworth MS et al (1978) Patterns of Attachment: A Psychological Study of the Strange Situation. Erlbaum, Hillsdale NJ.

Alsop-Shields L, Mohay H (2001) John Bowlby and James Robertson: theorists, scientists and crusaders for improvements in the care of children in hospital. Journal of Advanced Nursing. 35, 1, 50-58.

Aubuchon M (1958) To stay or not to stay parents are the question. Hospital Progress. 39, 170-177.

Bowlby J (1969) Attachment and Loss. Volume 1: Attachment. Basic Books, New York NY.

Bowlby J (1973) Separation: Anger and Anxiety. Random House, London.

Bowlby J (1980) Loss: Sadness and Depression. Random House, London.

Brown J, Ritchie J (1989) Nurses' perceptions of their relationships with parents. Maternal-Child Nursing Journal. 18, 2, 79-96.

Brown J, Ritchie J (1990) Nurses' perceptions of parent and nurse roles in caring for hospitalized

Burlingham D, Freud A (1942) Young Children in War-time London. Allen and Unwin, London.

Burlingham D, Freud A (1944) Infants Without Families: The Case For and Against Residential Nurseries. Allen and Unwin, London.

Callery P (1997a) Caring for parents of hospitalised children: a hidden area of nursing work. Journal of Advanced Nursing. 26, 5, 992-998.

Callery P (1997b) Paying to participate: financial, social and personal costs to parents of involvement in their children's care in hospital. Journal of Advanced Nursing. 25, 4, 746-775.

Court D (1975) Sir James Spence. Archives of Disease in Childhood. 50, 2, 85-89.

Coyne I (2008) Disruption of parent participation: nurses' strategies to manage parents on children's wards. Journal of Clinical Nursing. 17, 23, 3150-3158.
Fanselow MS (1994) Neural organization of the defensive behaviour system responsible for fear. Psychonomic Bulletin and Review.

1, 4, 429-438.

Fawcett J (1989) Analysis and Education of Conceptual Models of Nursing. FA Davis, Philadelphia PA.

Fegran L et al (2008) Development of parent-nurse relationships in neonatal intensive care units from closeness to detachment. Journal of Advanced Nursing. 64, 4, 363-371.

Fleury S et al (1954) Visiting in the pediatric department. The Canadian Nurse. 50, 292-294.

Fonagy P, Target M (2005) Bridging the transmission gap: an end to an importan mystery of attachment research? Attachment and Human Development. 7, 3, 333-343.

Forres H (1953) Emotional dangers to children in hospital. Mental Health. 12, 58-65.

Frank R (1952) Parents and the pediatric nurse. American Journal of Nursing. 52, 76-77.

Gill KM (1987) Nurses' attitudes toward parent participation: personal and professiona characteristics. Children's Health Care. 15, 3 149-151.

Gill KM (1993) Health professionals' attitude toward parent participation in hospitalized children's care. Children's Health Care. 22, 4, 257-271.

Godfrey A (1955) A study of nursing care designed to assist hospitalized children and their parents in their separation. Nursing Research 4, 2, 52-69.

Gofman H, Schade G (1957) Parents' emotional response to child's hospitalization. American Journal of Diseases of Children. 93, 6, 629-637.

Harlow HF, Zimmerman RR (1959) Affectional responses in the infant monkey. Science. 130, 3373, 421.

Johnson A, Lindschau A (1996) Staff attitudes toward parent participation in the care of children who are hospitalized. Pediatric Nursing. 22, 2, 99-102.

Jolley J (2004) A Social History of Pediatric Nursing: 1920-1970. Unpublished PhD thesis. University of Hull, Hull.

Jolley J, Shields L (2009) The evolution of family centered care. Journal of Pediatric Nursing. 24 2, 164-170.
Jongkees LBW (1955) Doctors, hospitals and children. British Journal of Physical Medicine. 18, 11-14.

Kain ZN et al (2004) Trends in the practice of parental presence during induction of anesthesia and the use of preoperative sedative premedications in the United States, 1995-2002: results of a follow-up national survey. Anesthesia and Analgesia. 98, 5, 1252-1259.

Knafl K et al (1988) Pediatric Hospitalization: Family and Nurse Perspectives. Scott and Foresman, Glenview IL.

Levy D (1945a) Child patients may suffer psychic trauma after surgery. Modern Hospital. $65,6,51-58$

Levy D (1945b) Psychic trauma of operations in children. American Journal Diseases Childhood. $69,7,7-25$.

Manongi RN et al (2009) Conflicting priorities: evaluation of an intervention to improve nurse-parent relationships on a Tanzanian paediatric ward. Human Resources for Health. $7,50,50-60$.

McCann ME, Kain ZN (2001) The management of pre-operative anxiety in children: an update. Anesthesia and Analgesia. 93, 1, 98-105.

Meadow SR (1969) The captive mother. Archives of Disease in Childhood. 44, 235, 362-367.

Ministry of Health (1959) The Welfare of Children in Hospital: Report of a Committee of the Central Health Services Council. Her Majesty's Stationery Office, London.

O’Haire S, Blackford JC (2005) Nurses' moral agency in negotiating parental participation in care. International Journal of Nursing Practice. 11, 6, 250-256.

Pickerill C, Pickerill H (1946) Keeping mother and baby together. British Medical Journal. 2, 4470, 337.

\section{Pongjaturawit Y et al (2006) Paren} participation in the care of hospitalized young children. Thai Journal of Nursing Research. 10 1, 18-28.

Priddis LE (2008) Tuned In Parenting (TIP): collaborative approach to improving parent-child relationships. Australian Journal of Community Psychology. 20, 2, 58-73.

Priddis LE, Wells G (2010). An innovative group approach to working with families to improve parent/infant relationships within a community setting. Journal of Neonatal, Paediatric and Child Health Nursing. 13, 3, 3-9.
Rendle-Short J (1965) Mothers in hospital with their children: experiences with a mother-in unit. Australian Paediatric Journal. 1, 98.

Robertson J (1970) Young Children in Hospital. Tavistock, London.

Roden J (2005) The involvement of parents and nurses in the care of acutely-ill children in a non-specialist paediatric setting. Journal of Child Health Care. 9, 3, 222-240.

Seidl F (1969) Pediatric nursing personnel and parent participation: a study in attitudes. Nursing Research. 18, 1, 40-44.

Seidl F, Pilliteri A (1967) Development of an attitude scale on parent participation. Nursing Research. 16, 1, 71-73.

Shields L (1999) A Comparative Study of the Care of Hospitalized Children in Developed and Developing Countries. $\mathrm{PhD}$ thesis. University of Queensland, Brisbane.

Shields L (2002) The parent-staff interaction model of pediatric care. International Pediatric Nursing. 17, 6, 442-449.

Shields L, Nixon J (1998) I want my mummy. Changes in the care of children in hospital. Collegian. 5, 2, 16-19.

Simmons W (1983) Report: Queensland Study Tour, 20th February to 1st March, 1983. Association for the Welfare of Children in Hospital, Sydney.

Slade A (2005) Parental reflective functioning: an introduction. Attachment and Human Development. 7, 3, 269-281.

Spence J (1947) The care of children in hospital. British Medical Journal. 1, 4490, 125-130.

Spitz RA, Wolf KM (1946) Anaclitic depression; an inquiry into the genesis of psychiatric conditions in early childhood, II. Psychoanalytic Study of the Child. 2, 313-342.

Vaughan G (1957) Children in hospital. The Lancet. 1, 272, 1117-1120.

Wood C (1888) The training of nurses for sick children. Nursing Record. 1, 507-510.

Yapp CS (1915) Children's Nursing: Lectures to Probationers. Poor Law Publications, London.

Yipp P et al (2009) Non-pharmacological interventions for assisting the induction of anaesthesia in children. Cochrane Database of Systematic Reviews. Issue 3. 
Copyright of Paediatric Nursing is the property of RCN Publishing Company and its content may not be copied or emailed to multiple sites or posted to a listserv without the copyright holder's express written permission. However, users may print, download, or email articles for individual use. 